\title{
BMJ Open Anticoagulant therapies for acute venous thromboembolism among a cohort of patients discharged from Canadian urban and rural hospitals
}

\author{
Tammy J Bungard, ${ }^{1}$ Bruce Ritchie, ${ }^{2}$ Jennifer Bolt, ${ }^{3}$ William M Semchuk ${ }^{3}$
}

To cite: Bungard TJ, Ritchie $B$, Bolt J, et al. Anticoagulant therapies for acute venous thromboembolism among a cohort of patients discharged from Canadian urban and rural hospitals. BMJ Open 2018;8:e022065. doi:10.1136/ bmjopen-2018-022065

- Prepublication history for this paper is available online. To view these files, please visit the journal online (http://dx.doi. org/10.1136/bmjopen-2018022065).

Received 30 January 2018 Revised 23 August 2018 Accepted 28 August 2018

Check for updates

(c) Author(s) (or their employer(s)) 2018. Re-use permitted under CC BY-NC. No commercial re-use. See rights and permissions. Published by BMJ.

${ }^{1}$ Division of Cardiology, University of Alberta, Edmonton, Alberta, Canada

${ }^{2}$ Division of Hematology, University of Alberta, Edmonton, Alberta, Canada

${ }^{3}$ Pharmacy Services, Regina Qu'Appelle Health Region, Regina, Saskatchewan, Canada

Correspondence to

Dr Tammy J Bungard;

tammy.bungard@ualberta.ca

\section{ABSTRACT}

Objective To determine anticoagulant therapy at hospital discharge for patients with acute venous thromboembolism (VTE) and secondarily, to describe factors affecting choice of therapy.

Design A retrospective chart review.

Setting Canadian hospitals in Edmonton, Alberta $(n=4)$, Regina, Saskatchewan $(n=2)$ and rural Alberta $(n=3)$ from April 2014 to March 2015.

Participants All patients discharged with an acute VTE were screened. Those with atypical clots, another indication for anticoagulation, pregnancy/breast feeding or lifespan $<3$ months were excluded.

Primary and secondary outcomes Primarily, we identified the proportion of patients discharged from hospital with acute VTE that were prescribed either traditional therapy (parenteral anticoagulant \pm warfarin) or a direct oral anticoagulant (DOAC). Secondarily, management based on setting, therapy choice based on deep vein thrombosis (DVT) versus pulmonary embolism (PE), clot burden and renal function was compared. DOAC dosing was assessed (when prescribed), length of hospital stay based on therapy was compared and planned follow-up in the community was described.

Results Among the 695 patients included, most were discharged following a diagnosis of PE $(82.9 \%)$ on traditional therapy (parenteral anticoagulant \pm warfarin) (70.2\%) with follow-up by either a family doctor $(51.5 \%)$ or specialist/clinic (46.9\%) postdischarge. Regional variation was most evident between urban and rural sites. Of those prescribed a DOAC (28.3\%), the majority were dosed appropriately (85.8\%). DOAC use did not differ between those with DVT and PE, was proportionately higher for less severe clots and declined with worsening renal function. Patients prescribed DOACs versus traditional therapy had a shorter length of stay (4 vs 7 days, respectively).

Conclusions Uptake of DOAC therapy for acute VTE was modest and may have been influenced by the timing of the audit in relation to the approval of these agents for this indication. Future audits should occur to assess temporal changes and ongoing appropriateness of care delivery.

\section{INTRODUCTION}

After over half a century of vitamin K antagonists as the only available oral anticoagulant
Strengths and limitations of this study

- This study consists of a large cohort of patients discharged with acute deep vein thrombosis or pulmonary embolism from two urban areas and three rural sites throughout an entire year, thereby providing a good reflection of practice patterns.

- All patient charts were reviewed for inclusion, thereby enabling accurate data capture of the acute venous thromboembolism (VTE) population.

- Although this audit occurred early in the licensing of direct oral anticoagulants (DOACs) for VTE, these data offer a benchmark for future usage as guidelines more aggressively incorporate the utilisation of DOACs in this population.

- Given our study design, we were not able to collect data for patients following discharge from hospital, thereby prohibiting the assessment of patient outcomes.

therapy, several direct oral anticoagulants (DOACs) have been approved within the past 5 years for the acute treatment of venous thromboembolism (VTE). ${ }^{1-4}$ Large scale trials have reported non-inferiority for efficacy and similar (or improved) rates of major bleeding with the DOACs relative to traditional therapy. ${ }^{5-10}$ Moreover, the DOACs (rivaroxaban, dabigatran, apixaban and edoxaban) offer advantages over the traditional therapy of an injectable anticoagulant (typically low-molecular-weight heparin (LMWH)) overlapped with warfarin. ${ }^{11}$ Unlike warfarin therapy, all DOACs have standardised dosing regimens that lack the need for routine coagulation monitoring and offer a therapeutic effect within hours of administration. Rivaroxaban and apixaban do not require initial therapy with an injectable anticoagulant, further streamlining care delivery.

While guidelines in $2012^{12}$ recommended the management of deep vein thrombosis (DVT) on an outpatient basis, only more 
recent guidelines $(2016)^{13}$ suggest the management of those with a low-risk pulmonary embolism (PE) at home or following a short length of stay in hospital. With both changing recommendations for managing DVT/ $\mathrm{PE}$ alongside the emergence of new and more streamlined anticoagulant options, patterns of practices for managing VTE among those discharged from hospital across both urban and rural sites has not been well characterised in the literature. As such, among a cohort of patients discharged from hospital with acute VTE, we hypothesised a modest early adoption of DOACs across both urban and rural sites in preference to traditional therapies, with DOAC uptake anticipated to be most prevalent in those with less severe clots.

\section{METHODS}

\section{Data sources}

For each institution, medical records were retrieved and reviewed by trained data abstractors (two for Alberta-based sites and one for Regina-based sites). All data elements (demographics, DVT vs PE, anticoagulant prescribed at discharge and follow-up plan in the community) were extracted as per the documentation in the hospital-based record and directly entered into the Research Electronic Data Capture (REDCap) program. As this was a retrospective chart review, missing data elements (such as weight) were identified and reported, accordingly.

\section{Study setting}

Reflective of a collaboration of local investigators, this retrospective chart review was conducted at the four largest hospitals in Edmonton, Alberta (University of Alberta Hospital, Royal Alexandra Hospital, Misericordia Hospital, Grey Nuns Hospital), three rural hospitals in Alberta (Wetaskiwin Hospital, Westlock Healthcare Centre and Athabasca Healthcare Centre) and the two hospitals in Regina, Saskatchewan (Regina General Hospital and Pasqua Hospital). Given that Alberta and Saskatchewan are two neighbouring provinces in Canada having different health authorities with different geographical distributions, data for the urban sites of Edmonton and Regina were kept separate and compared, accordingly.

\section{Patient population}

All patients with a discharge diagnosis of DVT (International Classification of Diseases (ICD)-10 code I82 +subindices) or PE (ICD-10 code I26 +subindices) between 1 April 2014 and 31 March 2015 were screened. Atypical clot locations (eg, axillary/subclavian veins, portal vein) were not included given their lack of enrolment in the large scale non-inferiority trials of the DOACs. ${ }^{5-10}$ Patients were also excluded if they had another indication for therapeutic anticoagulation (eg, mechanical heart valve, atrial fibrillation), were not discharged alive, had an anticipated lifespan $<3$ months (documentation of palliation or prognosis), were $<18$ years of age, were discharged directly from the emergency department or were pregnant or breast feeding.

\section{Outcomes}

Primarily, we sought to determine the proportion of patients discharged from hospital with acute VTE that were prescribed a traditional therapy (parenteral anticoagulant \pm warfarin) or a DOAC. Secondarily, we sought to compare differences in management between those in the Edmonton area, Regina area and rural Alberta. Use of DOACs for PE versus DVT was compared, as well as whether clot burden influenced anticoagulant selection. DVT was classified as proximal (at or above the popliteal vein including the trifurcation area) or distal in the leg. For PE, the validated simplified Pulmonary Embolism Severity Indices (sPESI) of either 0 or $\geq 1$ was used, calculated at the time of presentation of the PE. ${ }^{1415}$

When prescribed, the use of DOACs was assessed for concordance with dosing regimens with Health Canada approved product monographs as per prescriptions received both in hospital and as planned at the point of discharge. ${ }^{1-4}$ DOAC dosing was considered concordant if therapy was provided with either a parenteral anticoagulant or the appropriate up front (larger dose) of rivaroxaban (15 mg two times a day) or apixaban (10 $\mathrm{mg}$ two times a day) for the appropriate duration (3 and 1 week, respectively). We also assessed the difference in length of hospital stay in patients prescribed a DOAC versus a traditional therapy, and with whom follow-up was to occur after discharge.

Notably, these data represent a detailed evaluation specific to patients hospitalised with acute VTE. Our audit also encompassed the cohort of patients discharged directly from emergency departments from all institutions. As per our preplanned analysis, separate evaluations of the emergency department cohort ${ }^{16}$ as well as an evaluation comparing the emergency department cohort to the hospitalised cohort ${ }^{17}$ have been performed, and these companion papers will be published together even though all were not accepted on the same date.

\section{Patient and public involvement statement}

Patients and or the public were not involved in this study.

\section{Analysis}

Data analysis was performed at the Epidemiology Coordinating and Research Centre. All data are contained within REDCap, University of Alberta, and are available to the principal investigator (TJB). No data sharing agreement is in place. Data were collated and reported based on location, namely Edmonton area, Regina area and rural Alberta. Patients' characteristics were compared between sites using mean (SD) or median (IQR) as appropriate for the continuous data 


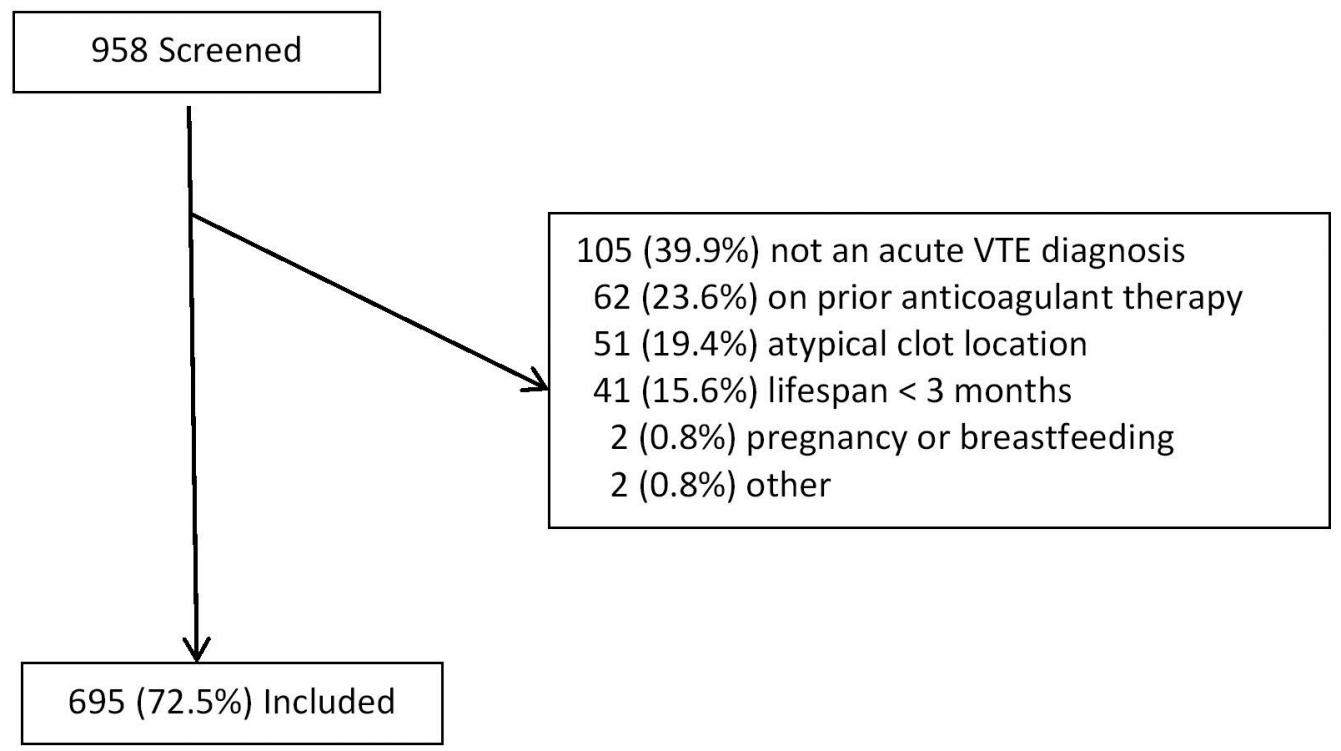

Figure 1 Patient flow chart. VTE, venous thromboembolism.

and proportions (\%) for categorical data. $\chi^{2}$ test was used to compare discharge therapies between sites and different groups. Statistical analysis was carried out on SAS V.9.4.

\section{RESULTS}

A total of 958 charts were screened with 695 (72.5\%) included (figure 1). The most common reasons for exclusion were lack of an acute VTE diagnosis (39.9\%) and another indication for therapeutic anticoagulation $(23.6 \%)$. Overall, those included had an average age $( \pm \mathrm{SD})$ of $63.3 \pm 17.3$ years, a median body weight of $85.5 \mathrm{~kg}$ and only a minority $(3.5 \%)$ had a creatinine clearance $(\mathrm{CrCl})<30 \mathrm{~mL} / \mathrm{min}$ (table 1$)$. The majority of patients had PE $(82.9 \%)$, particularly in the urban centres of Edmonton $(84.4 \%)$ and Regina $(80.8 \%)$, while the diagnosis of PE was lower in rural Alberta (63.3\%). Based on the sPESI score, the majority with PE in Edmonton $(66.5 \%)$ and Regina $(58.8 \%)$ had a PESI score $\geq 1$, while rural Alberta was nearly half the patients $(47.4 \%)$. The majority of patients admitted for DVT had a proximal clot; Edmonton (87.1\%), rural Alberta (81.8\%), Regina $(69.6 \%)$. Of note, full leg ultrasounds were used in Regina while only above the knee ultrasounds were used in both Edmonton and rural Alberta.

The majority of patients $(70.2 \%)$ were discharged from hospital on a traditional therapy (parenteral anticoagulant \pm warfarin), with $28.3 \%$ receiving a DOAC (table 2 ). Notably, Regina had the highest rate of a warfarin-based regimen $(60.8 \%)$, with less warfarin used in Edmonton $(40.5 \%)$ and rural Alberta $(30 \%) \quad(\mathrm{p}<0.0001)$. Use of DOACs was most common in rural Alberta $(57.9 \%)$, followed by Edmonton (28.3\%) and Regina (23.3\%) $(\mathrm{p}<0.0001)$.

There was no difference in proportionate use of a DOAC for PE compared with DVT $(28.0 \%$ and $30.3 \%$, respectively; $\mathrm{p}=0.61)$. Patients having a sPESI score of 0 were more likely to be prescribed a DOAC relative to those with a score $\geq 1 \quad(33.3 \%$ and $24.3 \%$, respectively; $\mathrm{p}<0.0001)$. Only a small portion of patients in our study had distal DVTs $(n=13)$ compared with proximal DVTs $(\mathrm{n}=99)$, leaving too few to perform statistical comparisons.

Among the 197 patients prescribed a DOAC, the majority $(97.5 \%)$ received rivaroxaban, with a minority of patients receiving apixaban $(\mathrm{n}=3(1.5 \%))$ and dabigatran $(n=2(1.0 \%))$. DOAC dosing for the acute treatment of VTE was consistent with product monographs in $85.8 \%$ of patients. The majority of inconsistent dosing with rivaroxaban was attributable to not having a full 3 weeks of therapy of higher dose (rivaroxaban $15 \mathrm{mg}$ two times a day) prior to implementing the lower maintenance dose of $20 \mathrm{mg}$ daily $(\mathrm{n}=25 / 28)$. Among these 25 patients, 5 had $<7$ days of rivaroxaban $15 \mathrm{mg}$ two times a day and 10 patients completed both 7-14 and 14-20 days of this regimen. Only a minority of patients had renal dysfunction with a $\mathrm{CrCl}<30 \mathrm{~mL} / \mathrm{min}(\mathrm{n}=23(3.5 \%))$. DOAC use declined with worsening renal function with $31.1 \%$ $(161 / 517), 19.0 \%(23 / 121)$ and $4.4 \%$ (1/23) prescribed a DOAC with a $\mathrm{CrCl}>50,30-50$ and $<30 \mathrm{~mL} / \mathrm{min}$, respectively $(\mathrm{p}<0.0001)$.

Combining all sites, median (IQR) length of stay was shortest among those prescribed a DOAC (4 days (2.0, 9.0) ) and longest for those transitioning from LMWH to warfarin therapy $(7$ days $(4.0,12.0))(\mathrm{p}<0.0001)($ table 3$)$. At discharge, among the urban sites follow-up was to occur most commonly with a VTE clinic/specialist $(47.5 \%$ for Edmonton and $52.5 \%$ with Regina) whereas rural Alberta referred most to family doctors $(66.7 \%)$ (table 2 ).

\section{DISCUSSION}

Among all sites, the majority $(70.2 \%)$ of patients presenting with acute VTE were prescribed traditional 


\begin{tabular}{|c|c|c|c|c|}
\hline & Total & Edmonton & Rural Alberta & Regina \\
\hline Screened (N) & 958 & 736 & 41 & 181 \\
\hline Included (N, \%) & $695(72.5)$ & $545(74.0)$ & $30(73.2)$ & $120(66.3)$ \\
\hline Male (N, \%) & $350(50.4)$ & $282(51.7)$ & $16(53.3)$ & $52(43.3)$ \\
\hline Mean age $($ mean $\pm S D)$ & $63.3 \pm 17.3$ & $63.8+17.2$ & $64.2+16.9$ & $60.4+17.6$ \\
\hline Weight documented $(\mathrm{N}, \%)^{\star}$ & $680(97.8)$ & $534(98.0)$ & 28 (93.3) & $118(98.3)$ \\
\hline Weight, kg (median, IQR) & $85.5(70.0,106.0)$ & $84.5(70.0,106.0)$ & $84.3(71.0,98.3)$ & $90.5(70.0,110.0)$ \\
\hline $\mathrm{CrCl}$ documented $(\mathrm{N}, \%)^{*}$ & $661(95.0)$ & $515(94.5)$ & $29(96.7)$ & $117(97.5)$ \\
\hline$<30 \mathrm{~mL} / \mathrm{min}$ & $23(3.5)$ & $20(3.9)$ & $1(3.5)$ & $2(1.7)$ \\
\hline $30-49 \mathrm{~mL} / \mathrm{min}$ & $121(18.3)$ & $96(18.6)$ & $3(10.3)$ & $22(18.8)$ \\
\hline$>50 \mathrm{~mL} / \mathrm{min}$ & $517(78.2)$ & $399(77.5)$ & $25(86.2)$ & $93(79.5)$ \\
\hline \multicolumn{5}{|l|}{ VTE } \\
\hline DVT (N, \%) & $119(17.1)$ & 85 (15.6) & $11(36.6)$ & $23(19.2)$ \\
\hline Distal & $13(10.9)$ & $7(8.2)$ & 0 & $6(26.1)$ \\
\hline Proximal† & $99(83.2)$ & $74(87.1)$ & $9(81.8)$ & $16(69.6)$ \\
\hline Not documented & $7(5.9)$ & $4(4.7)$ & $2(18.2)$ & $1(4.3)$ \\
\hline $\mathrm{PE}$ and PE+DVT‡ (N, \%) & $576(82.9)$ & $460(84.4)$ & $19(63.3)$ & $97(80.8)$ \\
\hline PE-simplified PESI score:§ (N, \%) & $567(98.4)$ & $451(98.0)$ & $19(100)$ & $97(100)$ \\
\hline 0 point & $201(35.4)$ & $151(33.5)$ & $10(52.6)$ & $40(41.2)$ \\
\hline$\geq 1$ point & $366(64.6)$ & $300(66.5)$ & $9(47.4)$ & $57(58.8)$ \\
\hline \multicolumn{5}{|l|}{ History of: (N, \%) } \\
\hline Cancer & $158(22.7)$ & $119(21.8)$ & $10(33.3)$ & $29(24.2)$ \\
\hline Pulmonary disease & $143(20.6)$ & $114(20.9)$ & $6(20.0)$ & $23(19.2)$ \\
\hline Prior VTE & $100(14.4)$ & $81(14.9)$ & $6(20.0)$ & $13(10.8)$ \\
\hline Recent surgery & $32(4.6)$ & $23(4.2)$ & 0 & $9(7.5)$ \\
\hline Length of stay (median, IQR) & $6.0(3.0-11.0)$ & $6.0(3.0-11.0)$ & $5.5(3.0-13.0)$ & $6.0(3.0-9.0)$ \\
\hline
\end{tabular}

*Not all patients had weight and serum creatinine documented in the chart.

†Combined popliteal, femoral, common femoral and iliac.

$\ddagger$ Combined PE with PE+DVT and report it all as PE.

$\S P E S I$ score could not be calculated in nine patients due to missing variable(s).

$\mathrm{CrCl}$, creatinine clearance; DVT, deep vein thrombosis; PE, pulmonary embolism; PESI, Pulmonary Embolism Severity Index; VTE, venous thromboembolism.

therapies (parenteral anticoagulant \pm warfarin) at hospital discharge, and 28.3\% received a DOAC. Rural Alberta had the greatest uptake of the DOACs $(50 \%)$, followed by the Edmonton area (28.3\%) and Regina area (23.3\%). Uptake of DOACs in rural Alberta is likely attributable to many factors, including more limited laboratory availability for routine coagulation testing, primary care physicians providing care within the hospital and hospital pharmacists who were comfortable with data pertaining to the use of DOACs in this population. While we found no difference in the use of DOACs for PE relative to DVT, DOACs were used more in patients with lower risk PE and normal renal function. When prescribed, the majority of DOAC use $(85.8 \%)$ was concordant with Canadian product labelling.

Our overall rate of DOAC use for acute VTE (28.3\%) is similar to that reported among 328 patients discharged from Florence, Italy hospitals following acute PE (32.5\%) during 2014 and 2015. ${ }^{18}$ These investigators assessed a time interval that partially overlapped with ours, and report an increase in DOAC use from 2014 (23.2\%) to $2015(40.1 \%)$. A single site evaluation of therapy for an incident VTE presentation among 256 patients in Montreal, Quebec Canada in 2013 found similar overall trends to our study with most patients being treated with warfarin $(54.7 \%)$ followed by LMWH alone $(27.7 \%)$ and rivaroxaban $(17.6 \%) .{ }^{19}$ Unlike our study, those in the Quebec evaluation with DVT $(\mathrm{n}=94)$ were more likely than those with PE $(n=162)$ to receive rivaroxaban $(28.7 \%$ and $11.1 \%$, respectively). In terms of clinical presentation of $\mathrm{PE}$, a single site evaluation of 39 patients with $\mathrm{PE}$ being discharged from hospital on a DOAC showed more use among those defined as low risk $(83 \%)$, with overall DOAC use still being high for those at intermediate to low risk (40\%), intermediate to high risk $(68 \%)$ and high risk $(40 \%) .{ }^{18}$ Our study found similar results in that more 
Table 2 Therapy at discharge and follow-up plan for hospitalised cohort

\begin{tabular}{|c|c|c|c|c|c|}
\hline & Total (\%) & Edmonton (\%) & Rural Alberta (\%) & Regina (\%) & P values \\
\hline VTE (all combined) & & & & & $<0.0001^{*}$ \\
\hline Parenteral AC alone & $185(26.6)$ & $160(29.4)$ & $6(20.0)$ & $19(15.8)$ & \\
\hline Parenteral $\mathrm{AC}+$ warfarin & $145(20.9)$ & $83(15.2)$ & $4(13.3)$ & $58(48.3)$ & \\
\hline Warfarin & $158(22.7)$ & $138(25 . \%)$ & $5(16.7)$ & $15(12.5)$ & \\
\hline DOAC & $197(28.3)$ & $154(28.3)$ & $15(50.0)$ & $28(23.3)$ & \\
\hline Rivaroxaban & $192(97.5)$ & $151(98.1)$ & 14 (93.3) & $27(96.4)$ & \\
\hline Dabigatran & $2(1.0)$ & 0 & $1(6.7)$ & $1(3.6)$ & \\
\hline Apixaban & $3(1.5)$ & $3(2.0)$ & 0 & 0 & \\
\hline Not documented & $10(1.4)$ & $10(1.8)$ & 0 & 0 & \\
\hline $\mathrm{PE}$ and $\mathrm{PE}+\mathrm{DVT}$ & & & & & $<0.0001^{*}$ \\
\hline Parenteral AC alone & $146(25.3)$ & $129(28.0)$ & $5(26.3)$ & $12(12.4)$ & \\
\hline Parenteral $\mathrm{AC}+$ warfarin & $129(22.4)$ & $77(16.7)$ & $1(5.3)$ & $51(52.6)$ & \\
\hline Warfarin & $132(22.9)$ & $119(25.8)$ & $2(10.5)$ & $11(11.3)$ & \\
\hline DOAC & $161(28.0)$ & $127(27.6)$ & $11(57.9)$ & $23(23.7)$ & \\
\hline Rivaroxaban & $156(96.9)$ & $124(97.6)$ & $10(90.9)$ & $22(95.6)$ & \\
\hline Dabigatran & $2(1.2)$ & 0 & $1(9.1)$ & $1(4.4)$ & \\
\hline Apixaban & $3(1.9)$ & $3(2.4)$ & 0 & 0 & \\
\hline Not documented & $8(1.4)$ & $8(1.7)$ & 0 & 0 & \\
\hline DVT alone & & & & & $0.045^{\star}$ \\
\hline Parenteral AC alone & 39 (32.8) & $31(36.5)$ & $1(9.1)$ & $7(30.4)$ & \\
\hline Parenteral $\mathrm{AC}+$ warfarin & $16(13.4)$ & $6(7.1)$ & $3(2.7)$ & $7(30.4)$ & \\
\hline Warfarin & $26(21.8)$ & $19(22.4)$ & $3(27.3)$ & $4(17.4)$ & \\
\hline DOAC & $36(30.3)$ & $27(31.8)$ & $4(36.4)$ & $5(21.7)$ & \\
\hline Rivaroxaban & $36(100)$ & 27 (100) & $4(100)$ & $5(100)$ & \\
\hline Dabigatran & 0 & 0 & 0 & 0 & \\
\hline Apixaban & 0 & 0 & 0 & 0 & \\
\hline Not documented & $2(1.7)$ & $2(2.4)$ & 0 & 0 & \\
\hline \multicolumn{6}{|l|}{ Follow-up† } \\
\hline Family doctor & $358(51.5)$ & $276(50.6)$ & $20(66.7)$ & $62(51.7)$ & $P=0.23$ \\
\hline VTE clinic & $202(29.1)$ & $201(36.9)$ & $1(3.3)$ & 0 & $\mathrm{P}<0.001$ \\
\hline Specialist & $124(17.8)$ & $58(10.6)$ & $3(10.0)$ & $63(52.5)$ & $P<0.001$ \\
\hline Anticoagulation clinic & $34(4.9)$ & $10(1.8)$ & 0 & $24(20.0)$ & $P<0.001$ \\
\hline Return to ED & $10(1.4)$ & $8(1.5)$ & $2(6.7)$ & 0 & $P=0.045$ \\
\hline Other & $101(14.5)$ & $90(16.5)$ & $6(20.0)$ & $5(4.2)$ & \\
\hline Not documented & $41(5.9)$ & $33(6.1)$ & $2(6.7)$ & $6(5.0)$ & \\
\hline
\end{tabular}

*P value compares therapies (categorised as parenteral anticoagulant alone, parenteral anticoagulant with warfarin, warfarin or a direct acting anticoagulant) used across the three settings.

†Not mutually exclusive.

AC, anticoagulant; DOAC, direct oral anticoagulant; DVT, deep vein thrombosis; ED, emergency department; PE, pulmonary embolism; VTE, venous thromboembolism.

patients with a sPESI score of $0(33.3 \%)$ received DOACs, however, DOACs were still used among those with a score of $\geq 1(24.3 \%)$.

Concordance with dosing for acute VTE in our study (85.8\%) was similar to that reported in an audit assessing the appropriateness of DOAC prescribing among 39 VTE patients in Australia $(84.6 \%)^{20}$ and lower than that reported in a non-interventional study assessing the use of the appropriate initial dosing of rivaroxaban $(93.7 \%) .^{21}$ Unlike our study wherein the majority of patients not receiving DOAC dosing per the product monographs was due to not receiving the appropriate up front rivaroxaban $15 \mathrm{mg}$ two times a day, the non-interventional study reported that only $73 \%$ of patients went onto step down 
Table 3 Length of stay in days (median, IQR) based on therapy

\begin{tabular}{lcccc}
\hline Therapy & All & Edmonton & Rural Alberta & \multicolumn{1}{l}{ Regina } \\
\hline DOAC & $4(2.0-9.0)$ & $4(2.0-8.0)$ & $6(2.0-19.0)$ & $4.5(2.0-8.5)$ \\
Parenteral alone & $5(3.0-10.0)$ & $5(2.0-9.0)$ & $15(5.0-21.0)$ & $6(4.0-10.0)$ \\
Parenteral+warfarin/warfarin alone & $7(4.0-12.0)$ & $8(4.0-14.0)$ & $4(2.0-6.0)$ & $7(4.0-9.0)$ \\
P values & $<0.0001$ & $<0.0001$ & 0.091 & 0.223 \\
\hline
\end{tabular}

DOAC, direct oral anticoagulant.

to rivaroxaban $20 \mathrm{mg}$ daily. ${ }^{21}$ Unfortunately, we were not able to identify therapy changes beyond that planned at hospital discharge within our study.

Given that initial therapy with an injectable anticoagulant is not required for both rivaroxaban and apixaban and that routine coagulation monitoring is not performed with all of the DOACs, care delivery with DOACs compared with traditional therapy with a parenteral anticoagulant \pm warfarin should be simplified. Data from the North American cohort of patients enrolled in landmark trials reports a significantly shorter length of stay for those receiving rivaroxaban (3.0 days (3.0-5.0)) compared with traditional therapy (4.0 days (3.0-6.0); $\mathrm{p}=0.0004) .{ }^{22}$ A single site evaluation in Quebec, Canada affirmed the clinical trial data, and reported median length of stay to be shorter with rivaroxaban use (3.5 days) relative to LMWH alone or warfarin therapy (6 days). ${ }^{19}$ Similarly, a single American institution identified those discharged on rivaroxaban compared with warfarin had shorter hospital stays (3.5 and 7 days, respectively; $\mathrm{p}<0.001) .{ }^{23}$ Our study also identified a shorter length of stay among patients receiving a DOAC, consistent with these data (table 3). ${ }^{19} 2223$ Our results, however, may have been confounded by those having more severe thrombosis receiving traditional therapies.

\section{STRENGTHS AND LIMITATIONS}

Herein, we present a large cohort of patients with acute VTE being discharged following hospitalisation. For all sites, we reviewed all medical records with a discharge diagnosis of DVT (ICD-10 code I82 +subindices) or PE (ICD-10 code I26 +subindices) over the span of a full year (April 2014 to March 2015). In doing so, different sample sizes were identified from each area, with rural Alberta and Regina having fewer patients $(\mathrm{n}=30$ and $\mathrm{n}=120$, respectively) than the Edmonton area $(n=545)$. Despite the differences in sample sizes, these data reflect local practices given the geographical populations and catchment areas (Edmonton: 1328290 plus catchment of 500 000; Regina: 230020 plus catchment of 500 000; rural Alberta 3 sites: 30065 ) and that an entire year was assessed. ${ }^{24-28}$ The timing of our audit is reflective of the early uptake of DOACs for the acute treatment of VTE given only rivaroxaban had Health Canada approval throughout the entire time interval audited. Provincial remuneration was only starting to occur, only being in place for rivaroxaban for the duration of the audit year for DVT in both provinces and for PE in June 2014 for Saskatchewan (beyond the audit year for PE in Alberta). Given the timing of approval and remuneration, prescribing patterns may have changed beyond the timing of this audit (March 2015). Despite this, we identified reasonable uptake of the DOACs (28.3\%), with use that complied with product monograph labelling in the vast majority $(85.8 \%)$. These data can serve as a marker for future analyses wherein usage can be compared to assess the uptake of this therapeutic approach over time as guidelines more aggressively incorporate the utilisation of DOACs in this population and clinicians become more comfortable with their use.

Our design (retrospective medical record review) was selected to allow us to accurately select patients with acute VTE to ascertain practice patterns. Given the diverse geography and volume of records to review, three data abstractors were necessary. A master key defining eligibility, data points to collect and how to code variables in REDCap was used. Within REDCap, restrictions for variables were programmed to minimise data entry error. Prior to finishing data collection at each site, quality assurance reports were performed to ensure accuracy of data. As this was a record review, we were limited only to information available in the hospital-based chart. Given this, some data elements were not documented (eg, weight, serum creatinine), leaving us to report data for those available. Moreover, our design did not enable us to collect data following hospital discharge, limiting us from determining if patients got their prescriptions filled or had complications following discharge.

\section{CONCLUSION}

In summary, we report the management of a large cohort of acute VTE patients being discharged from hospitals within Canada. Over a time interval early in the approval process for DOACs for the acute treatment of VTE, we report a modest update of DOACs $(28.3 \%)$ that were, overall, dosed correctly for the majority of patients $(85.8 \%)$. Variation in therapies used was evident with the most common regimen being warfarin based in Regina $(60.7 \%)$ and Edmonton $(40.5 \%)$ and a DOAC in rural Alberta $(50.5 \%) \quad(p<0.0001)$. Use of rivaroxaban was proportionately higher for less severe clots, and those prescribed a DOAC had a shorter length of stay relative to those given traditional therapies. As time evolves, it is anticipated use of DOACs will increase for the management of VTE. Practitioners and health delivery systems 
should continue to consider the opportunity provided by the DOACs to simplify and shorten hospital-based care as further data emerge to support their place in therapy. Future evaluations should occur to assess temporal changes, ongoing appropriateness of care delivery and the impact that DOACs may have on healthcare system resource allocation.

Contributors TJB contributed to the design of the work, the acquisition, analysis and interpretation of the data. TJB drafted the original manuscript, approved the final version to be published and is accountable for all aspects of the work related to accuracy or integrity. BR contributed to the design of the work, the interpretation of the data and critically revised the manuscript. BR approved the final version to be published and is accountable for all aspects of the work related to accuracy or integrity. JB contributed to the acquisition and interpretation of the data, critically revised the manuscript and approved the final version to be published. $\mathrm{JB}$ is accountable for all aspects of the work related to accuracy or integrity. WS contributed to the design, acquisition and interpretation of the data, critically revised the manuscript and approved the final version to be published. WS is also accountable for the accuracy and integrity of this work.

Funding Funding was received from Pfizer Canada (via TJB) in the form of an unrestricted grant.

Competing interests TJB has received honoraria for an advisory board for Boehringer Ingelheim, as well as honoraria for speaking from Bayer. TJB has received unrestricted grants from Pfizer and Leo Pharma Canada. BR has served on advisory boards, given sponsored lectures using his own slides and received travel expense remuneration for Bayer, Baxter, Beohringer-Ingelheim, CSL-Behring, Pfizer, Sanofi, Servier and Shire. In lieu of honoraria for these activities, the companies have given financial contributions to the University of Alberta. BR reports grants from Novo Nordisk, CSL-Behring and Baxter, all outside of this submitted work. $\mathrm{JB}$ has received speaker honoraria from Boehringer Ingleheim in the past 2 years. WS has received honoraria from Bayer, Pfizer, Bristol Myers Squibb and Boehringer Ingleheim. He has served as a consultant or on an advisory board for Bayer and Pfizer/Bristol Myers Squibb and he has received an unrestricted research grant from Pfizer.

\section{Patient consent Not required.}

Ethics approval Health Research Ethics Board approval was received through the University of Alberta (Pro00056384) for all Alberta sites, and via the Regina Qu'Appelle Health Region (REB 15-65) for the Regina sites.

Provenance and peer review Not commissioned; externally peer reviewed.

Data sharing statement There is no data sharing agreement-this is included in the original research article.

Open access This is an open access article distributed in accordance with the Creative Commons Attribution Non Commercial (CC BY-NC 4.0) license, which permits others to distribute, remix, adapt, build upon this work non-commercially, and license their derivative works on different terms, provided the original work is properly cited, appropriate credit is given, any changes made indicated, and the use is non-commercial. See: http://creativecommons.org/licenses/by-nc/4.0/.

\section{REFERENCES}

1. Pfizer Canada Inc, Bristol-Myers Squibb Canada. ELIQUIS ${ }^{\mathrm{TM}}$ product monograph. http://www.pfizer.ca/sites/g/files/g10028126/f/201607/ ELIQUIS_PM_184464_16June2016_E_marketed.pdf (accessed 9 Feb 2017).

2. Daiichi Sankyo, Inc, Parsippany, NJ, USA (Manufacturer). Progress therapeutics, newmarket, ontario (importer and distributer). Lixiana ${ }^{\mathrm{TM}}$ product monograph. https://pdf.hres.ca/dpd_pm/00037831.PDF (accessed 9 Feb 2017).

3. Boehringer Ingelheim Canada Ltd. Pradax product monograph. https://www.boehringer-ingelheim.ca/sites/ca/files/documents/ pradaxapmen.pdf (accessed 9 Feb 2017).

4. Bayer Inc. Xarelto ${ }^{\text {TM }}$ product mongraph. http://omr.bayer.ca/omr/ online/xarelto-pm-en.pdf (Accessed 9 February 2017).
5. Agnelli G, Buller HR, Cohen A, et al. Oral apixaban for the treatment of acute venous thromboembolism. N Engl J Med 2013;369:799-808.

6. Schulman S, Kearon C, Kakkar AK, et al. Dabigatran versus warfarin in the treatment of acute venous thromboembolism. N Engl J Med 2009;361:2342-52.

7. Schulman S, Kakkar AK, Goldhaber SZ, et al. Treatment of acute venous thromboembolism with dabigatran or warfarin and pooled analysis. Circulation 2014;129:764-72.

8. Bauersachs R, Berkowitz SD, Brenner B, et al. Oral rivaroxaban for symptomatic venous thromboembolism. N Engl J Med 2010;363:2499-510.

9. Büller HR, Prins MH, Lensin AW, et al. Oral rivaroxaban for the treatment of symptomatic pulmonary embolism. N Engl J Med 2012;366:1287-97.

10. Büller HR, Décousus H, Grosso MA, et al. Edoxaban versus warfarin for the treatment of symptomatic venous thromboembolism. $N$ Engl J Med 2013;369:1406-15.

11. Finks SW, Trujillo TC, Dobesh PP. Management of venous thromboembolism: recent advances in oral anticoagulation therapy. Ann Pharmacother 2016;50:486-501.

12. Kearon C, Akl EA, Comerota AJ, et al. Antithrombotic therapy for VTE disease: antithrombotic therapy and prevention of thrombosis, 9th ed: american college of chest physicians evidence-based clinical practice guidelines. Chest 2012;141:e419S-94.

13. Kearon C, Akl EA, Ornelas J, et al. Antithrombotic therapy for VTE disease: CHEST guideline and expert panel report. Chest 2016;149:315-52.

14. Chan CM, Woods C, Shorr AF. The validation and reproducibility of the pulmonary embolism severity index. $J$ Thromb Haemost 2010;8:1509-14.

15. Righini M, Roy PM, Meyer G, et al. The Simplified Pulmonary Embolism Severity Index (PESI): validation of a clinical prognostic model for pulmonary embolism. J Thromb Haemost 2011;9:2001-7.

16. Bungard TJ, Ritchie B, Bolt J, et al. Management of acute venous thromboembolism among a cohort of patients discharged directly from the emergency department. BMJ Open 2018;0:e022064.

17. Bungard TJ, Ritchie B, Bolt J, et al. Anticoagulant therapies for acute venous thromboembolism: a comparison between those discharged directly from the emergency department versus hospital in two Canadian cities. BMJ Open 2018;0:e022063.

18. Masotti L, Vannucchi V, Poggi M, et al. Trends in length of hospital stay in acute pulmonary embolism over the years. What is changing in the era of direct oral anticoagulants? J Cardiovasc Med 2017;18:817-23.

19. Dault R, Vanasse A, Blais L, et al. Patterns and predictors of use of anticoagulants for the treatment of venous thromboembolism following approval of rivaroxaban. Clin Appl Thromb Hemost 2016;22:765-71.

20. Pattullo CS, Barras M, Tai B, et al. New oral anticoagulants: appropriateness of prescribing in real-world setting. Intern Med $J$ 2016;46:812-8.

21. Ageno W, Mantovani LG, Haas S, et al. Safety and effectiveness of oral rivaroxaban versus standard anticoagulation for the treatment of symptomatic deep-vein thrombosis (XALIA): an international, prospective, non-interventional study. Lancet Haematol 2016;3:e12-e21.

22. Bookhart BK, Haskell L, Bamber L, et al. Length of stay and economic consequences with rivaroxaban vs enoxaparin/ vitamin $\mathrm{K}$ antagonist in patients with DVT and PE: findings from the North American EINSTEIN clinical trial program. $J$ Med Econ 2014;17:691-5.

23. Desai A, Desai A, Calixte R, et al. Comparing length of stay between patients taking rivaroxaban and conventional anticoagulants for treatment of venous thromboembolism. Lung 2016;194:605-11.

24. Population of Edmonton area. http://globalnews.ca/news/1824910/ edmonton-region-has-canadas-2nd-highest-population-growthstats-canada/ (accessed 31 Oct 2017).

25. Population of Regina. http://www.leaderpost.com/life/Regina+ population+cracks/9553267/story.html (accessed 31 Oct 2017).

26. Athabasca Population. http://www.city-data.com/canada/AthabascaTown.html (accessed 31 Oct 2017).

27. Westlock Population. http://www.city-data.com/canada/WestlockTown.html (accessed 31 Oct 2017).

28. Wetaskiwin Population. https://www.wetaskiwin.ca/DocumentCenter/ View/1039 (accessed 31 Oct 2017). 